\title{
"The Stuff You May Have Missed" Art, Film and Metareference in The Simpsons
}

\author{
Henry Keazor
}

\begin{abstract}
Since its beginnings as an autonomous show in 1989, the cartoon series The Simpsons has presented itself as a highly self-reflexive and metareferential creation. Already the title sequence - in itself an allusion to an earlier cartoon series, The Flintstones - introduces the audience to the richness and density of the (self-)references awaiting them, culminating in a scene where the Simpson family members gather in front of the television in order to watch their own show. Such metareferential strategies are further developed throughout the program, ranging from abundant references to cartoon history to hinting at The Simpsons' own quality as a graphically designed, two-dimensional and animated artifact. It is especially the heightened awareness of this medial quality which also motivates frequent metareferences to the visual arts and to film. These metareferences, however, do not only relate to the genre and production of the cartoon itself, but moreover serve as comments on the referenced works from other media, thus affording the opportunity to voice at times biting comments on cultural, social and political developments. Over the by now more than twenty years the program has been running, The Simpsons have to some extent shaped and nurtured the contemporary TV audience's skills in decoding and understanding self- and metareference. In terms of its popularity and remarkable self-reflexivity, it is one of the outstanding contributions to the metareferential turn in contemporary culture - which, in the case of the cartoon or animated film (as in other media) is not a sudden change in the nature of reference but rather a 'metareferential surge'.
\end{abstract}

\section{Las Simpsonas?}

Matt Groening's cartoon series The Simpsons, launched as an autonomous show in $1989^{1}$ (and has thus celebrated its $20^{\text {th }}$ anniversary in

1 Between 1987 and 1989 the Simpson characters appeared in short films which were part of the comedy program The Tracey Ullmann Show. For a concise history of The Simpsons as a show see Ortved 2009. The author also quotes voices (cf. 56-70, 211) raising the question to which extent The Simpsons can be considered a creation of Matt Groening's alone, since the series we know today is actually the product of a whole team, featuring mainly James L. Brooks, Sam Simon and Matt Groening as well as a dozen writers. Or, as Ortved sums up: "The Simpsons is, and always has been, a giant collaboration" (ibid.: 263). As Simpsons producer Richard Raynis, however, rightly suggests, Groening is by now functioning as a sort of a figurehead for the se- 
2009), is generally considered as a highly self-reflexive, self-referential and metareferential creation ${ }^{2}$. The extent to which this classification is justified can for example be seen in the fact that 'America's most dysfunctional family' (as the Simpsons have been called and almost hailed) has been taken up as a topic of an art project which aimed at a contemporary, modern adaptation of the epitome of the metareferential artwork: Diego Velázquez's world-famous painting Las Meninas (1656; see Illustrations 1 and 2, the latter showing a screen capture from the originally animated sequence, which is also accompanied by sound and music) . $^{3}$.

However, upon comparing the Meninas to this telling adaptation, it becomes evident that there are, in fact, more differences than similarities between the painting and the cartoon series. Velázquez's painting has frequently been praised for how it apparently incorporates the viewer into the composition, an effect most notably achieved through the life-size of the figures and the highly realistic style. In $1855 \mathrm{Sir}$ William Stirling-Maxwell, e. g., wrote that the painter had seemingly anticipated photography's early forerunner, the daguerrotype: "Velázquez seems to have anticipated the discovery of Daguerre and, taking a real room and real people grouped together by chance, to have fixed them, as it were, by magic, for all time, on canvas" (171). Moreover, the painting has often been lauded for virtually opening the depicted space toward the viewer, who thus feels invited to join the people represented in the painting by overstepping what has been called 'the aesthetic border' of an artwork ("ästhetische Grenze", Michalski 1932:

ries: "It's important that The Simpsons has Matt Groening [...] The audience feels like they're connecting with a creator" (qtd. Schreiber 1998).

2 Among the many statements which could be quoted here cf., e. g., Arnold, who considers the series "a self-parodic, self-referential pastiche of previous texts" (2001: 264), or Gray: "[...] The Simpsons relishes its self-referentiality and frequently engages in pastiche [...]" (2006: 5).

3 The animation Las Simpsonas, conceived and realised in 2002 by Matthias Dittgen, Roman Locher, Thomas Wittek, Philipp Köstner and Mathias Woywod, was part of a series of re-interpretations of Diego Velászquez's famous painting at the faculty for digital media at the University of Applied Sciences Furtwangen in the context of a seminar on media design. See http://webuser.fh-furtwangen.de/ fetzner/ meninas/gruppen.html and http://webuser.fh-furtwangen.de/ fetzner/meninas/works/ las_simpsonas/las_simpsonas-konzept.swf [29/03/2010]. Note the fact that Homer and Marge Simpson appear in the background mirror (or painting) and that the paintings on the wall (based on purchasable Simpsons postcards) parody famous artworks by substituting the Simpsons for the original protagonists. 
10; cf. also Stoichita 1997: 13-27). The effect of the painting can perhaps be best summed up in the famous exclamation of the French writer Théophile Gautier who, in front of the picture which seems to merge and blend with reality, thus obliterating its own status as an artwork, asked "Où est donc le tableau?" ("Where, now, is the painting?'), in order to reply to himself: "Ce n'est pas un tableau. C'est la vie prolongée" (qtd. Borel 2002: 59; 'This is not a painting. This is extended life').

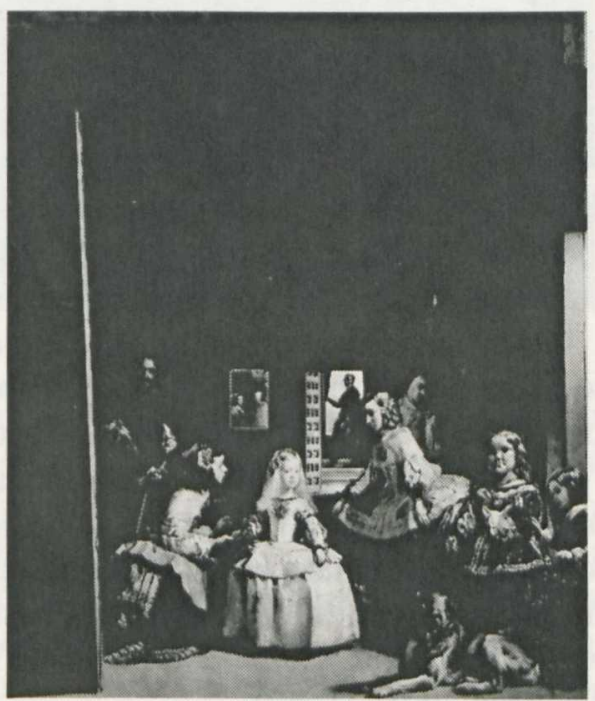

Illustration 1: Diego Velázquez, Las Meninas (1656). Museo del Prado, Madrid.

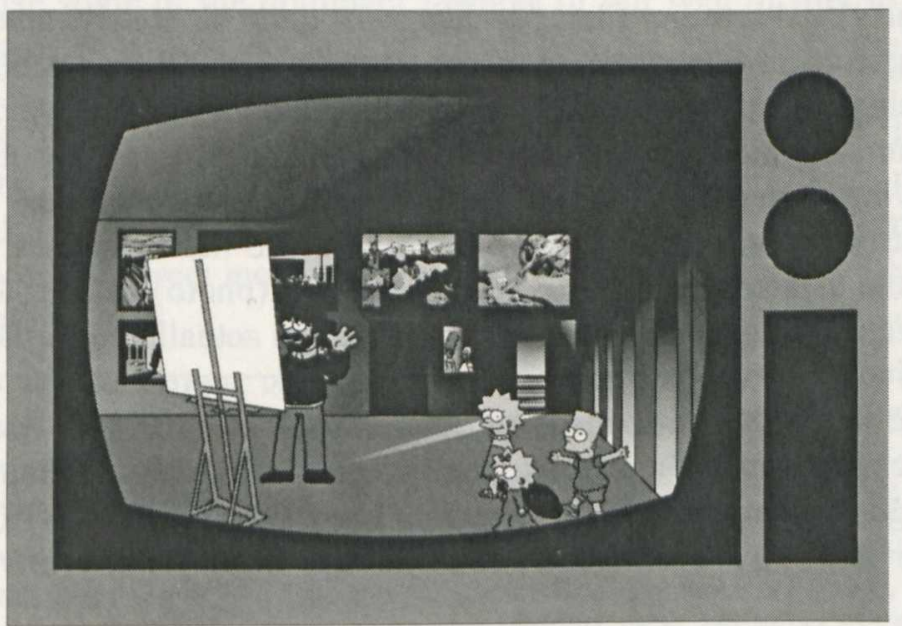

Illustration 2: Screen capture from Las Simpsonas. 
However, a brief look at The Simpsons suffices to see that Groening's is a completely different approach and ambition. His series is obviously not in the least interested in the illusionist virtuosity of painterly representation, close mimetic fiction, an apparent opening towards a fictitious reality, let alone aiming to merge with or perpetuate it. The same holds true for the filmic medium: given the obviously unambitious and rather caricaturised 'comic' appearance of the Simpson figures, they are apparently not conceived to render a realistic view of an artist via animated film either. The possible objection that this could be the result of the medial difference between painting and film can be rebutted with reference to the fact that the film camera has actually been considered an excellent means for communicating an artist's gaze as well as the resulting perception to the audience. This idea of a direct transition between painting and film - two media, which on the visual level of individual pictures and frames merely differ as to their technical means - was not only voiced by Alexandre Astruc, who compared the use of an artist's pencil to the use of the camera when coining the notion of the "camera-stylo" (see 1948), or suggested by Dieter Daniels's characterization of film as a 'continuation of painting with other means' ("Fortsetzung der Malerei mit anderen Mitteln"; 2002: 32), this notion of an intimate kinship between the pictorial and the filmic medium is, moreover, at the conceptual basis of films such as Peter Greenaway's The Draughtsman's Contract (1982; see Schuster 1998 and cf. Petersen 2001: 71-80).

Instead of pursuing the realistic and naturalistic possibilities of both the visual arts and film, The Simpsons quite obviously rather aim at a vigorous re-interpretation of the perceptual world by establishing and using its very own graphic system of representation, which depicts humans mostly with yellow skin, large, oval eyes, big mouths displaying an overbite, four fingers and very distinctive hairdos.

Thus it becomes evident that - in contrast to the Velásquez painting - the aspired aim here is not to render a (photo)realistic, highly mimetic and illusionist representation. One can actually go further and state that not even an approximately realistic representation as we know it from other cartoons is considered ${ }^{4}$ : this is even made humourously explicit and is metareferentially articulated with a certain bold and vigorous emphasis in the episode "Lady Bouvier's Lover" (1994/ Season 5/1F21), where Homer, in a brief daydream fantasy, envisions

\footnotetext{
4 Cf. Arnold on the cartoon in general: "[...] a medium that at once suggests and confutes the impression of verisimilitude" (2001: 253).
} 
his children Bart and Lisa in a more 'realistic' cartoon style, which he, however, considers a horror vision (see Illustration 3): "And then our kids... [...] horrible freaks with pink skin, no overbites, and five fingers on each hand!"

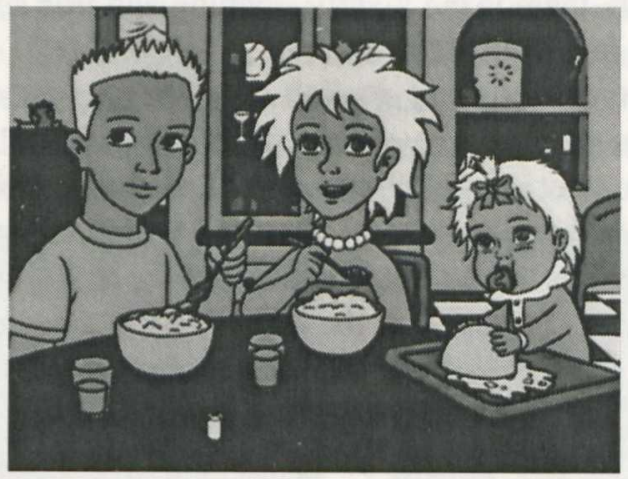

Illustration 3: Screen capture from "Lady Bouvier's Lover".

Homer's terse defense of the cartoon's very distinct and particular representational system (which Tom Wolfe has justifiably likened to a "child's style of drawing" [qtd. Ortved 2009: 260]) mirrors the consistent way in which it is applied as 'normal' throughout the whole series, thus consciously (and almost aggressively) opposing itself to the natural appearance of humans 5 . The outward appearance of the Simpson characters hence correlates to what Linda Hutcheon has diagnosed as a hallmark of the "postmodern's initial concern", which is "to denaturalize some of the dominant features of our way of life; to point out that those entities that we unthinkingly experience as natural $[\ldots]$ are in fact 'cultural'; made by us, not given to us" (1989: 2$)^{6}$.

This (in the The Simpsons' case literal) 'de-naturalization' has to be kept in mind when considering what is at issue in this essay, namely the different forms and functions of 'metareference' in the series as a facet of the current metareferential turn which is in focus in the present volume.

5 Cf. also Arnold: "The Simpsons gets its energy precisely from the conflict between our recognition of the signifiers as highly mediated, as un-realistic, and our understanding that they nonetheless resemble a reality we recognize". (2001: 259)

6 However, Mittell rightly (if not in an entirely consistent way) argues against the general categorization of The Simpsons as 'postmodern'. He first convincingly shows how vague and elusive the term is when applied to the show, but in the end he concedes that the notion "may be a compelling categorization of this program textually", while at the same time, inviting the reader to "look beyond the text" (2001: 26). 


\section{Forms of metareference in The Simpsons}

In the following I will give some examples for the various forms of metareference in The Simpsons.

To begin with, there is the famous opening and title sequence, which is self-reflexive in a fourfold manner:

1) First, in an obvious and explicit way, the sequence shows us the family members as they leave their different pursuits, which are all typical and characteristic of them: son Bart doing chalkboard exercises at school, which always hint upon the various offences that have earnt him a detention; father Homer overhastily and recklessly leaving his work as a safety inspector at the local nuclear plant in a way which already hints at the fact that his working morale is prone to dangerous accidents; daughter Lisa being expulsed from the school orchestra because of her extravagant (read: 'jazzy') way of playing the saxophone; and mother Marge and baby Maggie doing the shopping and driving home. The family ultimately meet at their house to gather "in front of the television set to watch, of all things, The Simpsons" (see Korte 1997: online). Thus, already the title sequence makes it clear that the Simpsons obviously watch their own series, and that we are watching it with them ${ }^{7}$. This is moreover emphasized by the 'couch gag', a recurring element which presents funny, inventful and sometimes extravagant variations on how the family members enter the living room and take their seats on the couch in front of the television, sometimes encountering absurd obstacles while doing so ${ }^{8}$.

7 Concerning this 'cooperative perception act' and its consequences cf., e. g., Arnold 2001: 265 or Gray 2006: 2 and 7, who even based the title - Watching with 'The Simpsons' - and the entire approach of his book on this. In following Rushkoff (cf. 2004: 296f.), Ortved quotes the Simpsons writer and producer Al Jean: "Some of the most creative stuff we write comes from just having the Simpsons watch TV" (2009: 110). Concerning the innovation of this concept see Ozersky, who describes the preceding situation as follows: "[...] TV has never shown us TV [...] depictions of the TV set on TV itself renders it invisible and omnipresent" (1991: 12). This is, of course, only true concerning mainstream entertainment; but already in 1971 the Austrian media artist Valie Export realized Facing a Family, an art project which consisted of a family being filmed and broadcasted on TV while watching a family watching TV. See http://www.valieexport.at/de/werke/ [29/03/2010].

8 For a list of the couch gags from seasons 1-8 cf. Groening/Richmond/Coffman 1997: 90f. Many of these already contain references to famous art works: in one couch gag the Simpsons's home resembles the impossible construction in M. C. Escher's litograph Relativity (1953) with its different sources of gravity, and thus the 
The cartoon characters watching their own series is, in fact, even taken up and accounted for in "Behind the Laughter", an episode which is conceived as a 'behind the scenes'-feature (2000/Season 21/ BABF 19; see Illustration 4a). It recounts that the Simpsons are actually a truely existing family, brought to TV by father Homer who was unhappy with the cliché-ridden way American families had been depicted on TV and thus decided to write, direct and shoot his own familyseries. His endeavour then turned out to be so successful that a big production company commissioned further episodes.
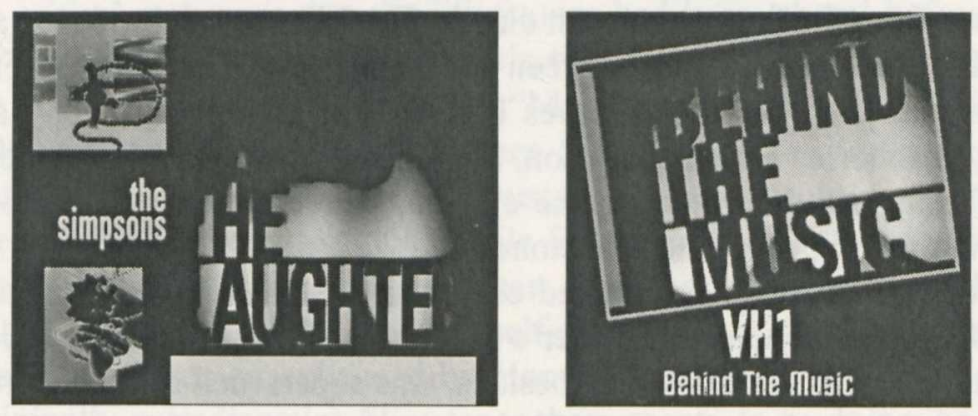

Illustration 4a (left): Screen capture from "Behind the Laughter".

Illustration $4 b$ (right): Screen capture from Behind the Music.

"Behind the Laughter" does not really tell a story; it is rather conceived as a fake metareferential disclosure-feature, exposing the typical scandals (the drug addiction of actors), bloopers (such as Bart not showing up for filming his scene), crises (such as 'secret' recasts, e. g. when Bart gets fired and is substituted by another cartoon character), fights behind the scenes, along with the painful consequences funny moments in the series actually had for the actors, the (fictitious) dramatic drops in audience rating as well as the shameless (non-fictitious) commercial exploitation of the series through merchandise products. Of course, the whole episode draws its comic potential from the fact that the viewer knows that all of these disclosures are fictitious, since the characters - as cartoon characters - cannot have a real, independent life behind the scenes, do not need rehearsals and will not provoke bloopers. However, what truly creates the humour of the episode is how references to real documentary TV productions such as Behind the Music (the VH1 biography show on which the fictitious show in the Simpsons episode is modelled; see Illustration $4 b$ ) and to actual 
facts (such as e. g. the star the Simpsons got on Hollywood Boulevard in 2000 or the fights among the producers about certain scripts) $)^{9}$ are at the same time put into the context of those fake 'disclosures'. As in the title sequence, we also see the Simpsons watching their own scenes on TV or reading their own comics throughout the episode ${ }^{10}$.

2) However, this metaleptic element is only one facet of the metareferentiality with which the viewer of The Simpsons is greeted at the very opening of each episode. In addition, the title sequence contains a noteworthy intramedial reference as it takes up and adapts the title sequence from the famous cartoon classic The Flintstones, produced and aired in the United States between 1960 and 1966. There, father Fred Flintstone is shown as he leaves his work in a similarly happy and hasty manner as Homer Simpson, also in order to return home, fetch his family and take them to the cinema, where they watch a movie starring, of all things: the Flintstones ${ }^{11}$.

Such references have incited critics to pit the Flintstones against the Simpsons, accusing the latter's producers of frequently using ideas from the earlier series, which, besides, was superseded as longest running cartoon program by Groening's show ${ }^{12}$.

Faced with such accusations, the Simpsons producers reacted in a pronounced and aggressive manner: In the episode "The Day Violence

9 Ortved (cf. 2009: 215), for instance, reports clashes between the producers of the show which even led to Groening removing his name from the credits of one disputed episode in 1995.

10 Another variation of the Simpsons's self-awareness of being on TV is given with one couch gag where Bart's image changes colour, as if appearing on a malfunctioning TV set. Homer then actually fiddles with the controls on the TV set, but only when he smacks Bart on the back of his head does his image stabilize.

11 This is actually the title sequence which was used from the second season of the Flintstones onwards - the first season simply featured Fred driving home and sitting in front of the television. Thus, the Simpsons title sequence presents a mix of these two Flinstones sequences, combining the family-gathering, the television and the viewing of the own series.

12 In the record-breaking episode "The Itchy \& Scratchy \& Poochie Show" (dethroning as episode no. 167 the 166 episodes of The Flintstones) there are several hints at that fact, starting with the plot itself which deals with a cartoon producer's desperate efforts to save his long-running but now faltering show. For more parallels between The Flintstones and The Simpsons see also Ortved 2009 who - following Mullen 2004 - not only emphasizes the fact that "[p]rime time had not seen an animated sitcom since The Flintstones" (3) but also sees the theme song from The Simpsons as "a mix of The Jetsons and The Flintstones" (80). 
Died" (1996/Season 7/3F16) - critizing The Flintstones while at the same time defending The Simpsons - they had a cartoon producer admit that "animation is built on plagiarism. If it weren't for someone plagiarizing The Honeymooners, we wouldn't have The Flintstones", which hints at the fact that the Flintstones characters were in turn closely modelled upon an earlier real-life comedy show ${ }^{13}$. Even before that, in 1992, the Simpsons producers had created a couch gag which directly confronted the Simpsons with the Flintstones, who were surprisingly occupying the Simpsons' sofa (thus ironically confirming the critics' statement that the Flintstones had been 'there' before). In the following year, the Flintstones's title sequence was even par for par restaged in the opening of the "Marge vs. the Monorail" episode $(1993 / \text { Season } 4 / 9 \mathrm{~F} 10)^{14}$ with Homer Simpson as the protagonist. It featured an array of absurd consequences prone to result from such an overly faithful modernization: while Fred could easily jump into his doorless stone-age car, Homer, when aping him, crashes through the closed car window. The inherent self-reflexivity of this Simpsons sequence is moreover enhanced by Homer intradiegetically singing the (originally extradiegetic) Flintstones theme song. In so doing, he does not only exchange his own name and that of his hometown, Springfield, for the Flintstones and Bedrock, but, in order to plunge the selfreflexivity into the completely absurd, his new lyrics also prophetically anticipate what is going to happen to him the next moment. Whereas the original Flintstones lyrics read:

Flintstones, meet the Flintstones,

They're a modern stoneage family.

From the town of Bedrock,

They're a page right out of history,

Homer sings:

Simpson, Homer Simpson,

He's the greatest guy in history.

From the town of Springfield

He's about to hit a chestnut tree,

an accident which ensues immediately afterwards.

3) The famous title sequence is moreover self-reflexive in a more indirect and implicit way in so far as it represents a ritual (and every

13 The Honeymooners was a popular American sitcom, aired between 1955 and 1956.

14 The whole episode itself is a takeoff on the film The Music Man (dir. Morton DaCosta 1962) - cf. Groening/Richmond/Coffman 1997: 104f. 
ritual to some extent refers to itself; see Turner 1969). The opening sequence always remains essentially the same, but in each episode it is interspersed with particular new elements. Thus, it presents a well balanced mix of the old and accustomed and the new and fresh. The varying elements are:

a. Bart's lines on the chalkboard,

b. Lisa's saxophone solos,

c. the couch gags ${ }^{15}$.

This means that the audience can expect something new among the old and familiar every time, which, however, means that the changes and innovations are incorporated into the conventionalised ritual. Moreover, some of the title sequences' elements are occasionally taken up and referred to in the plots of particular episodes, which shows that in The Simpsons self-reflexive moments are generated out of almost all elements.

4) The range of self- and metareferences in the title sequence is, however, not restricted to hints at the The Simpsons' antecedents and paragons (such as The Flintstones). Frequently the cartoon genre at large becomes the referential object. There is, for instance, one couch gag in which the Simpsons appear in the vest of an early classic cartoon, rendered in black and white and wearing white gloves (Illustration $5 a$ ), accompanied by a variation of their title song in rather flat and muffled sound quality typical of early cartoon films from the $1920 \mathrm{~s}^{16}$.
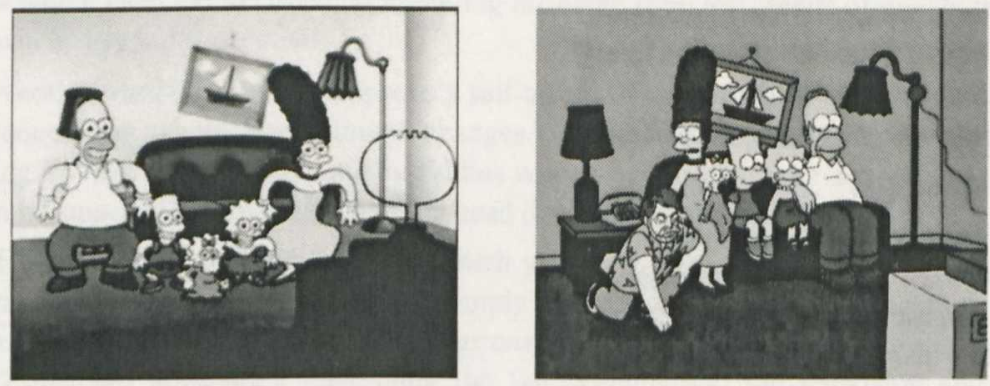

Illustration $5 a$ (left) and $5 b$ (right): Screen captures from The Simpsons.

15 Henry just labels these three elements generally as "self-consciously altered each week" (1994: 95) without giving any further explanation.

16 In another couch gag of that type, the Simpsons resemble characters from the famous cartoon studio Hanna-Barbera (responsible also for The Flintstones); in tone with that studio's humour, they are depicted as persistently grinning while running past the couch in front of a ever-recurring background. 
As can be expected, the metareferential variety and density of the title sequence is only a prelude to a no less diversified and ingenious continuation of metareferentiality in the ensuing episodes, only some of which can be mentioned in the following.

Another title sequence climaxes in a couch gag where creator Matt Groening makes a brief metaleptic appearance in order to reinstate his signature on the film frame which an overly orderly Marge had wiped clean (see Illustration $5 b$ ).
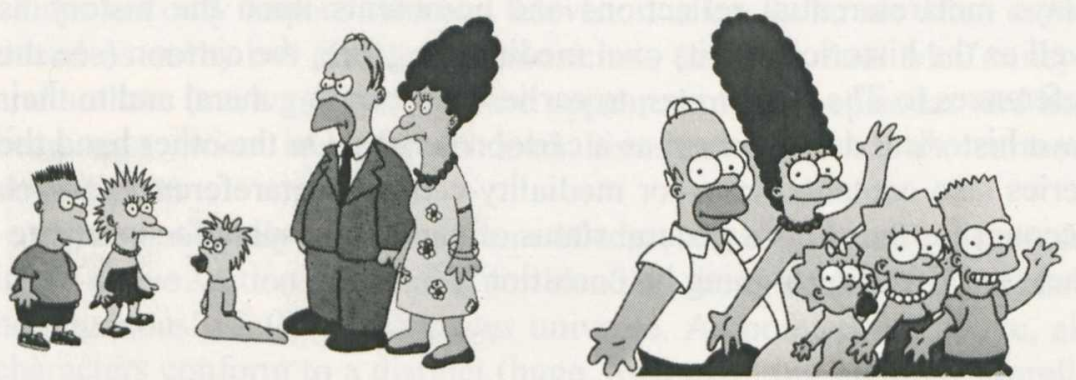

Illustration $6 a$ and 6b: The Simpsons as they appear on The Tracey Ullman Show (left) and on The Simpsons (right).

While it is usually Bart and/or Lisa who provide the solution to problems around which the plots are centred, this is not the case in the aforementioned episode "The Day the Violence Died". Here, Lester and Eliza take over that part, two children who perfectly resemble the Bart and Lisa prototypes of the days when The Simpsons were still a feature of the Tracey Ullman Show (see Illustrations $6 a$ and $6 b$ ). This reference to the history and the development of the cartoon characters, whose appearance was still much 'rougher' in the beginning ${ }^{17}$, is, however, not gratuitous. It actually echoes the plot of the episode which deals with the history of Itchy \& Scratchy, Bart and Lisa's favourite cartoon show ${ }^{18}$. At the same time the episode is a counter-example of

\footnotetext{
17 According to the BBC documentary The Simpsons: America's First Family (2000), Groening had only delivered rough and basic sketches for the characters, assuming that the animators would refine and smoothen them further during production. However, the animators accepted them as they were and only added colour. For the choice of colours cf. Ortved 2009: 51-53.
}

18 Already the title of the episode is an allusion, referring to Don McLean's famous song "American Pie" from 1971 which features the line "The day the music died". This was meant to refer to the $3^{\text {rd }}$ February 1959, when the musicians Buddy Holly, Ritchie Valens and J. P. Richardson died in a plane crash. The cartoon-within-thecartoon "Itchy \& Scratchy Show" is not only a parody of cartoon shows such as Tom \& Jerry, but rather - as Cantor has rightly put it - in its abandonment of any kind of 
the fact that sometimes elements and motifs, first introduced in the title sequences, are then taken up in the episodes, since a similar confrontation between the former and the present look of the cartoon family occurred later, in 1999, in a couch gag which has the two 'versions' of the Simpsons meet during their race towards the sofa where they scare each other to such an extent that they all run away, screaming with horror.

As these cases in point show, The Simpsons on the one hand displays metareferential reflections and comments upon the history as well as the historicity of its own medium or genre, the cartoon (see the references to The Flintstones, to earlier cartoons in general and to their own historical development as a cartoon series). On the other hand the series also contains fictio- or mediality-centred metareferences which account for the show's general status or nature as a manufactured artefact (see Groening signing his 'creation') 19

\section{The 'metahappy' Simpsons ${ }^{20}$}

Since pictorial media (such as, e. g., drawings or painted images) ${ }^{21}$ and their animation are among the constituting elements of the car-

story in favour of the depiction of pure violence "the quintessence of cartoon" (1997: 34), thus again a reference to The Simpsons' own medium. See also Butler/Sepp 2007.

19 With Savage one could continue and deduce that, thus, the audience's awareness of the cartoon as a product, i. e. "as an object of commerce and therefore of the whole corporate system, the dominant culture" (cf. 2004: 200) is enhanced. As stated above, the aforementioned episode "Behind the Laughter" relates to the audience how the show is commercially exploited through a huge range of mass-produced goods. A mixture of both, the emphasis on the Simpsons as a manufactured product and as a source for commercial exploitation, lies at the heart of the title sequence for the episode with the telling title "MoneyBART" (2010/Season 22/MABF18/SI-2118). It was designed by British street artist Banksy and cuts from the sofa scene to an exaggerated depiction of the hellish, dungeon-like conditions under which this particular scene as well the whole series are produced in a South Korean sweatshop, where Simpsons merchandise is also manufactured and shipped. The sequence takes on critics who accused Groening of outsourcing to South Korea and it aroused protests against its alleged inherent hypocrisy and the depicted stereotypes concerning Asian work conditions.

20 "the metahappy Simpsons never had issue satirizing itself." (Ortved 2009: 117)

21 There is, e. g., a couch gag in which the image of the family, sitting on the sofa, is suddenly grabbed by a human, live-action hand which starts to spin the picture like a pottery wheel, provoking the outlines of the Simpsons to squirt into 'spin art'. 
toon, there are also numerous instances of The Simpsons which metareferentially refer to the visual arts and film ${ }^{22}$. As most films also comprise a sound dimension, these references work on a visual as well as on an acoustic level, and are thus not strictly limited to pictorial media, but also encompass others such as music and literature. Hence there are not only many references to, and quotes from, art works and films, but also from classical as well as popular music and from wellknown novels and poems. Moreover, the voice cast of the series includes not only famous film and television actors (who are often introduced as such) but also artists, musicians (such as Paul McCartney) and authors (such as Thomas, who appeared in three episodes and has been cast twice in order to lend his own voice to his cartoon counterpart).

The specifically graphic system of representation briefly discussed in the above section 1 is crucial for blending these 'real-life' guest stars homogenously into the Simpsons universe. As pointed out above, all characters conform to a distinct (huge, oval eyes, big mouths), simplifying (four fingers) and idiosyncratic (yellow skin, overbites) representation of human beings. The guest stars as well as the artworks quoted in the series are subjected and adapted to this reprentational system. As a consequence, their portrayals in the series border on caricature $^{23}$, while the boundaries between life and art as established and distinguished in the cartoon are thus frequently blurred: Since the portraits Marge paints of the (young) ex-Beatle Ringo Starr in the episode "Brush with Greatness" (1991/Season 2/7F18) closely resemble the latter's (meanwhile aged) cartoon alter ego, her paintings obviously have to be understood as highly mimetic, if not photorealistic. The same contiguity between 'art' and 'life' in the cartoon can be observed in a scene from the episode "The Crepes of Wrath" (1990/ Season 1/7G13). After his arrival in France, where he is to spend some time on a student exchange programme, Bart is being driven through the setting of Édouard Manet's painting Le Déjeuner sur l'herbe (1863;

\footnotetext{
22 One couch gag has the Simpsons accidentically and metaleptically leave their film frame while running towards the couch.

23 Cf. also Groening's ironic comment: "For some reason a lot of Hollywood big shots are curious to see how they'd be drawn with bulging eyes and no chin" (qtd. Korte 1997: online). Concerning the characters in The Simpsons in general cf. furthermore McConnell: "So they are caricatures, not just of $u s$, but of us in our national delusion that the life of the sitcom family is the way things are 'supposed' to be" (1990: 390).
} 

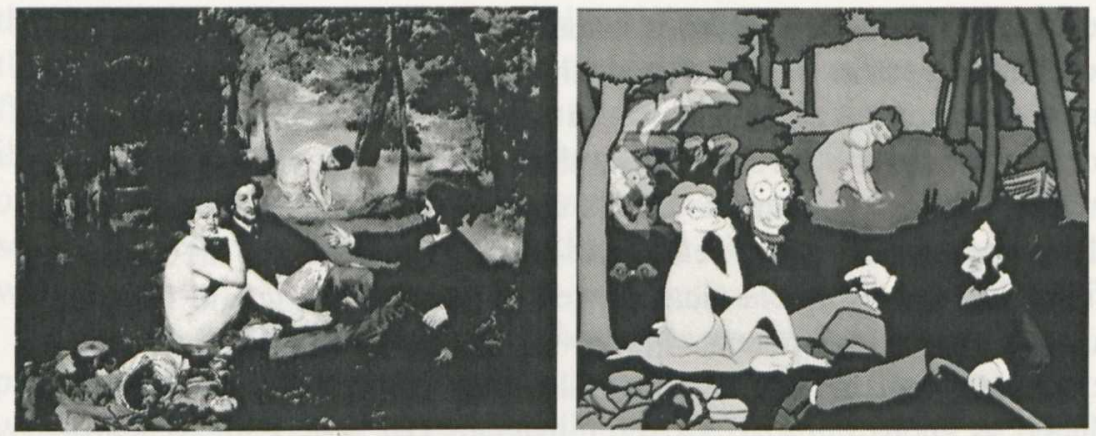

Illustration $7 a$ (left): Édouard Manet, Le Déjeuner sur 1'herbe (1863). Musée d'Orsay, Paris.

Illustration $7 b$ (right): Screen capture from "The Crepes of Wrath".

see Illustration 7a) in the sidecar of his host father's motorbike (Illustration $7 b)^{24}$. Here, too, the physiognomy of the protagonists in Manet's painting is adapted to the typical representational mode of the Simpsons universe, which causes the medial differences and borders between the cartoon characters and the protagonists in the quoted artwork to be both metareferentially highlighted and blurred. The blurring refers in particular to their fundamental kinship as twodimensional, draught and painted creations, which is thus enhanced. How important this enhancement is for the overall impression becomes apparent upon comparing scenes such as the ride through Manet's painting with similar instances in films such as Mary Poppins (Stevenson, dir. 1964) or Who Framed Roger Rabbit (Zemeckis, dir. 1988). In those cases the differences between the 'real' world and the world of the artwork, viz. the cartoon, are clearly maintained and even emphasized, due to the resulting juxtaposition: the 'real'-world characters might be able to metaleptically jump into paintings (Mary Poppins; see Illustration $7 c$ ), and cartoon characters might be able to step into the 'real' world (as does Roger Rabbit). However, as their appearances stay in tune with their respective 'worlds of origin', there always remains a clear distinction between the 'indigenous' inhabitants of the entered worlds and their 'bizarre' and temporary guests. As these distinctions are suspended in The Simpsons, entire characters and whole plot-motifs from cinematic films can be seamlessly inte-

24 The sequence of driving through the settings of this artwork and other paintings serve as a means to quickly evoke the hackneyed ideas and expectations usually attached to French culture and here also quickly shattered when Bart discovers that he has actually fallen into the hands of two evil winemakers. See also Keazor 2003. 
grated into the series. In the above-mentioned episode "The Crepes of Wrath", for instance, Bart's French host fathers, Ugolin and César, are, in terms of names and appearance, modelled on the two villains from the film adaptation of Marcel Pagnol's Jean de Florette (Berri, dir. 1986) ${ }^{25}$. All of this, however, only works for and can be understood by 'educated' Simpsons viewers due to the fact that the producers have previously established the specific representational frame analysed above, into which everything is adapted and fitted.

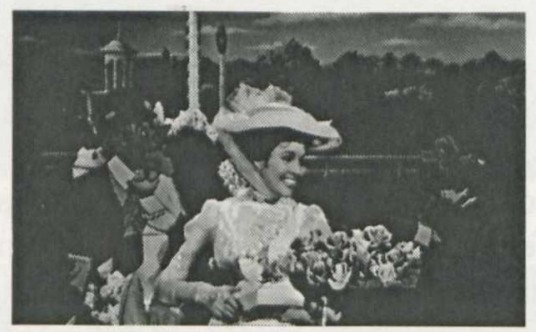

Illustration 7c: Screen capture from Marry Poppins.

Moreover, in examples such as Mary Poppins the filmic medium seems to try hard to veil its two-dimensionality: it identifies with the ontologically real, three-dimensional world by contrasting its characters against the two-dimensional world of the paintings into which they jump. In The Simpsons, on the other hand, the two-dimensionality of the cartoon is emphasized and 'defended' with almost the same vigour and aggressiveness as is its particular representational system in "Lady Bouvier's Lover". While in that episode beings without yellow skin, overbites and four fingers are presented as a horror vision, Homer, in the Halloween episode "Treehouse of Horror VI" (1995/Season $7 / 3 \mathrm{~F} 04$ ), travels through a so-called wormhole, a kind of gateway which connects the two-dimensional world of the cartoon world with our three-dimensional reality. He is thus transformed from a drawn cartoon character into a 'real', corporal being (which is the exact opposite of what usually happens to actual human characters who appear in The Simpsons). Subsequently, the two-dimensionality of the cartoon world is once more stressed in an explicitly self-reflexive way, when the series' scholar, Professor Frink, after having announced that Homer has been transferred into the third dimension, explains the nature of this dimension by underlining that three dimensional cubes are a reality: "Here is an ordinary square, $[\ldots]$ but suppose we extend the 
square beyond the two dimensions of our universe along the hypothetical $\mathrm{Z}$ axis, there. This forms a three-dimensional object known as a 'cube' $[\ldots]^{\prime 26}$. The gasping reaction of his audience clearly indicates that they are as frightened by this idea as Homer was horrified by three-dimensional physiognomy when looking at his children. Homer and the Simpsons in general seem to be happy or even 'meta-happy' to live in their two-dimensional world, a happiness which is tinged by a distinctly metareferential quality for us, the viewers.

\section{Creating an audience for its own genre}

In this section, a concluding example will demonstrate how the above discussed metareferential elements combine in one singe episode: "Mom and Pop Art" (1999/Season 10/AABF15). In this episode (see also Wolf 2006), Homer is accidentally 'discovered' and temporarily hailed as an 'outsider artist' while trying to get rid of the sad remains of his unsuccessful attempts to build a brick-barbecue. Trying to live up to this newly assigned status as artist and to deliberately create art works, he fails and falls into an inspirational crisis, which Marge tries to help him out of by suggesting a visit to the local museum. There, Homer falls asleep and dreams of being attacked by artworks (such as Leonardo da Vinci's famous Vitruvian Man) as well as by artists (as, for instance, by Andy Warhol, who threatens to batter him with one of his Campbell Soup cans). Puzzled by the dream as well as by his own lack of inspiration, Homer asks his little daughter Lisa what he should do in order to create art, and she replies that he should try to conceive "something big and daring". Trying to follow her advice, (in the wake of the Happening artists and Situationists ${ }^{27}$ ) he floods his hometown Springfield in order to transform it into a second Venice, thus recreating J. W. M. Turner's famous view of Venice (Illustration $8 a)^{28}$, which

\footnotetext{
${ }^{26}$ The two graphic novels L'Origine (1991) and Le Processus (1993) by Marc-Antoine Mathieu not only already tackle this very topic, in L'Origine Igor Ouffe, moreover, presents a diagram highly reminiscent of the one used by Frink to the novels' protagonist, Julius Corentin Acquefacques, in order to explain the nature of three-dimensionality to two-dimensional beings (cf. Mathieu 1991: 40). In Le Processus Acquefacques also switches from his two-dimensional world to a three-dimensional universe in a similar way as Homer does later in The Simpsons (cf. Mathieu 1993: 39-44).

27 Concerning especially the latter artistic movement see Plant 1992 and Ford 2004.
} 
Homer had seen at the museum (Illustration $8 b$ ). The final scene shows Marge painting the inundated Springfield (Illustration $8 c$ ).

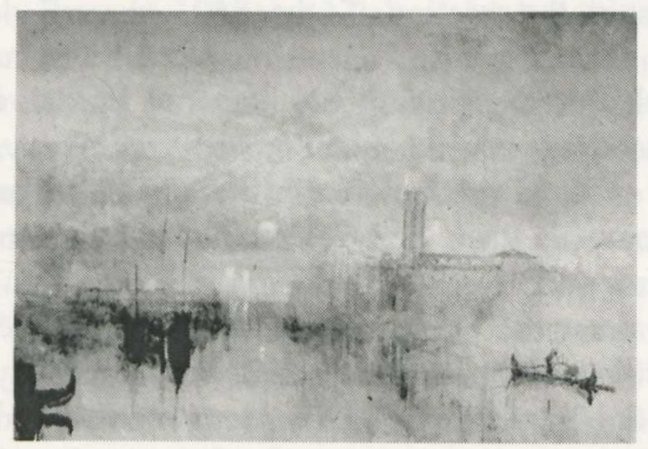

Illustration 8a: J. W. M. Turner, Moonrise (1840), London, Tate Britain.
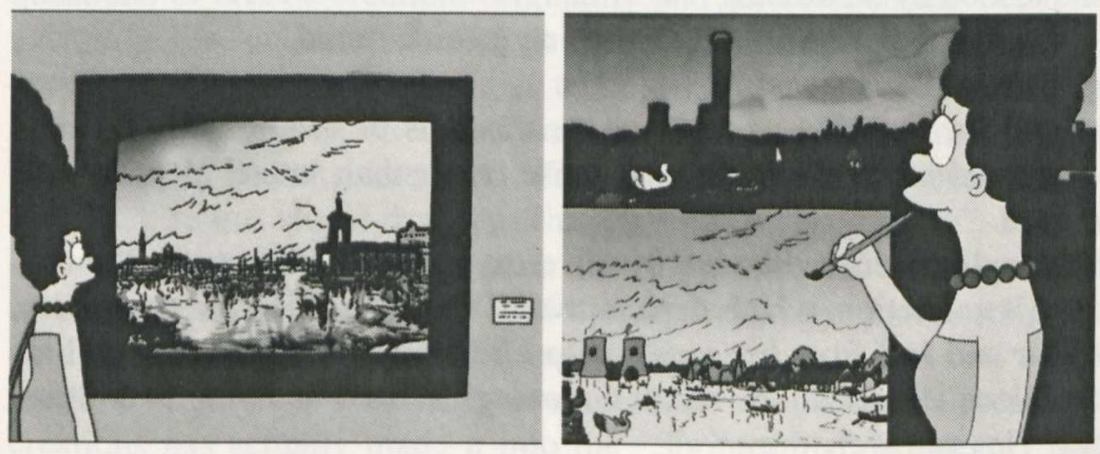

Illustration 8a (left) and $8 b$ (right): Screen captures from "Mom and Pop Art".

Thus, the episode metareferentially addresses interdependencies between art works as they often can be observed and studied in art history:

- Homer sees an artwork by Turner, which has a great impact on him: that is, he appears as an artist being inspired by another artist.

28 Examples such as this or the one involving Manet's Déjeuner also clearly demonstrate that the statement of Irwin/Lombardo concerning allusions to the visual arts in The Simpsons has to be revised; according to these authors the series' allusions to paintings are "less common" and "are overwhelmingly, though not exclusively, to American art works" (2001: 91). However, references to paintings are, in fact, rather frequent throughout the series and the choice of referenced art works seems less guided by their country of origin than by their celebrity - hence, there are frequent references to European art works. For these references see also Keazor 2003. 
- He interprets this artwork by adapting it to his reality (thus doing exactly what also the producers of The Simpsons do): art is thus shown to inspire the creation of other art.

- In the end, Homer's wife Marge transforms the resulting 'real' scenery back into a painting: art, inspired by art, is once again shown to encourage artistic creation.

In addition, all of these metareferential statements on artistic production are conspicuously made and reflected upon in a two-dimensional, pictorial medium: the cartoon.

In order to stress the interconnectedness and parallels in the production of painting and cartoons (inspiration, creativity, two-dimensionality etc.), the creators of The Simpsons have included a scene in the museum which contains strong self-reference towards the medium in question by addressing

- the fact that a cartoon is something manufactured,

- its two-dimensionality,

- and the question of whether a cartoon is or can actually be considered art in the traditional sense rather than 'mere' popular culture.

Homer discovers a drawing by his creator, Matt Groening, in the museum's collection, which depicts two of Groening's earlier characters, Akbar and Jeff from his comic strip Life in Hell ${ }^{29}$. Astonished and incredulous Homer utters: "Matt Groening? What's he doing in a museum? He can barely draw".

As if to punish him for these blasphemous remarks, a giant rubber appears, hitting his head and provoking Homer to scream: "Oh no - I am being erased!" This remark is not only a clear (meta)reference to his status as a cartoon character, but actually metaleptically hints at his self-awareness of being a character. However, the giant rubber eventually turns out to merely be part of a Claes Oldenburg sculpture (in this case representing a pencil), which is just being delivered to the museum. This, on the one hand, implies the vengeful intrusion of the creator (who seemingly threatens to erase the thankless and truculent creation that questions his artistic genius); this suggestion is, on the other hand, promptly and humorously disproved by one of The Simpsons' many intermedial references.

The motif of a cartoon creator interfering with one of his creations while drawing has been a generic topos almost since the beginning of 
cartoon art (see here, e. g., highlights such as the film Bobby Bumps Puts a Beanery on the Bum, directed by Earl Hurd and produced by John Randolph Bray in 1918, or Michael Maltese's and Charles M. Jones's cartoon Duck Amuck from 1953). As this example illustrates and many more could be found (see Feyersinger in this vol.) - metareference appears to have accompanied animated films/cartoons since the beginnings of this medium. However, this is not to say that metareference has not reached a new intensitiy and quality in cartoon series such as The Simpsons, thus producing what one may call a 'metareferential surge' (which in turn contributes to the transmedial metareferential turn). Indeed, metareference such as the metaleptically interfering cartoon creator acquires a new meaning in The Simpsons, as the aforementioned episode shows: it is part of of a plot which deals with questions of artistic creation, originality and the relationship between everyday life and art. The "Mom and Pop Art" episode, moreover, combines several metareferential techniques and statements, among them the recurring question and discussion of whether or not cartoons are or should be considered art. "Cartoons don't have any deep meaning. They're just stupid drawings that give you a cheap laugh", Homer had explained to his wife Marge in the earlier episode "Mr. Lisa Goes to Washington" (1991/Season 3/8F01), thus cleverly understating the case of The Simpsons and prone to stir objections. In fact, in "Mom and Pop Art", eight years and seven seasons later, one of Groening's creations has actually made it into the "Springsonian Museum"; and yet another fifteen years later, when, in the episode "Girls Just Want to Have Sums" (2006/Season 17/HABF12) - a clever parody of Barbara Streisand's 1983 film musical Yentl - Lisa steps into the hall of the new 'girls-only' school, a Cathy cartoon by Cathy Guisewite ${ }^{30}$ hangs in the distinguished company of art works by Frida Kahlo and Georgia O'Keeffe, thus implying that the cartoonist merits an equivalent position in the pantheon of female artists.

In conclusion I would like to address the question of why The Simpsons display such richness in metareferential practices. As noted above, some of these practices were already deployed earlier in the history of film and television ${ }^{31}$, but not with such frequency and such

30 Guisewite is an award winning cartoon artist who, in 1976, created Cathy, a comic strip about a career woman faced with the issues and challenges arising in the context of work, relationships, her mother and food.

${ }^{31}$ Cf., e. g., Mittell: "[...] Simpsons-style reflexivity and intertextuality have been features of television comedy since its first decade" (2001: 16). 
density. By way of explanation I would like to offer six reasons which partly interconnect:

1. Given the fact that the history of film and television has by now grown rich in its repertoire of metareferential strategies, the producers of The Simpsons have a large inventory of motives, ideas and inspirations to draw upon, and since many of the artistic crew pursued media studies or studies in the history of art before joining The Simpsons ${ }^{32}$, they are well aware of this repertoire.

2. Having matured as a medium, television has developed its own culture and history, which also serve as a sort of stock for hints and (meta)references.

3. In the past it was mainly TV series that had been running for a considerable length of time which employed metareferential strategies. Once they had firmly established themselves and their characters, they could start playing with this renown and allow themselves to become manneristic in a way, that is, to care less about the narrated content and more about narrative style. However, since the late 1990s, TV series have begun to sometimes show such heightened and manneristic complexity right from the beginning (as, e. g., David E. Kelley's Ally McBeal [1997-2002]) $)^{33}$. This might be due to the fact that their producers have learnt from the later, manneristic episodes of long-running TV shows, applying their techniques in order to make the new programmes outstanding and more appealing to a meanwhile saturated audience that demands less conventional and more sophisticated and complex concepts of a show ${ }^{34}$.

32 Cf. for this, e. g., Groening: "A lot of talented writers work on the show, half of them Harvard geeks. And you know, when you study the semiotics of Through the Looking Glass or watch every episode of Star Trek, you've got to make it pay off, so you throw a lot of study references into whatever you do later in life" (Qtd. Irwin/ Lombardo 2001: 81). Cf. also the statement by producer David Mikron: "We're really writing a show that has some of the most esoteric references on television. I mean really, really, really strange, odd, short little moments that very few people get and understand. We're writing it for adults and intelligent adults at that". (Qtd. ibid.)

33 For comedy, e. g., cf. Matheson: "[...] today's comedies tend to be highly quotational: many of today's comedies essentially depend on the device of referring to or quoting other works of popular culture" (2001: 109). Cf. also the reaction of Simpsons author Al Jean as reported by Rushkoff: "If you watch an old episode of I love Lucy, you'll find it laborious because they take so long to set something up" (2004: 299).

34 Cf. Irwin/Lombardo: "Audiences enjoy being involved in the creative process; they enjoy filling the blanks for themselves rather than being told everything" (2001: $85)$. 
4. This, however, only works when the audience is skilled enough to understand and follow such concepts, which audiences nowadays have become capable of. While in the past TV audiences had to first get acquainted with a new series in order to be able to understand its complex and possibly metareferential procedures, contemporary audiences are drawn to new shows because they offer and deploy such procedures right from the start ${ }^{35}$.

5. Thus one can observe something akin to the processes of the phyloand the ontogenesis in evolutionary development, as phrased in the (today however highly disputed, see, e. g., Gould 1977) "Fundamental Biogenetic Law" by Erich Haeckel: as an embryo progresses through evolutionary stages (which took its species ages to develop) in a mere few weeks, the average contemporary viewer, thanks to the media socialisation he or she grows up with in nowadays media-dominated society, likewise learns to follow and understand programs or films so rich in complex strategies such as metareferential procedures ${ }^{36}$ which audiences of previous generations would not have been able to immediately understand. "[A] steady diet of television has turned us all into budding 'media theorists' who have the capacity to critique and to shape the media that define us [...]". (Arnold 2004: 22f.) This grants us what David Bianculli has called "teleliteracy" (1992: 6), i. e., "an awareness of and facility with powerful cultural codes disseminated through television" (ibid.: 22).

6. The Simpsons themselves were and are part of such a media socialisation and formation: several years after the start of the series, the producers launched the publication of a series of guidebooks. As strange as it might seem that the audience of a cartoon show would need such assistance, it has to be remembered that The Simpsons,

unlike most humorous shows on television [...] does not employ the use of a laugh track to cue the viewer in to when it is being funny. Dozens of jokes, asides, and funny references are made in the course of an episode, but, due to the lack of a cue, go largely unnocticed. There are so many of these allusions in a given episode that often, one can watch that episode over and over again and pick up

35 Cf. Matheson: "The Simpsons was born [...] just as the use of quotationalism was maturing". (2001: 110)

36 Cf. Stabile/Harrison: "Assuming that its audience had grown up on a television diet, The Simpsons offers a text rich with allusions to a body of popular culture history roughly equivalent to the history of television". (2003: 9) 
new ones each time. The Simpsons is a program unique in its use of humor without a laugh track, in the way that it invites the viewers to pick out for themselves the lines and actions they think are funny, based on their own personal experiences and awareness of popular culture. (Korte 1997: online)

As their cover sticker reading "Characters, episodes, and secret jokes you might have missed" promises, the guidebooks explain some (but not all!) of the numerous and sometimes in fact very subtle, elaborate, demanding and sophisticated hints and (meta)references to literature, music, art, history, politics and society which occurred throughout the series' first fourteen seasons (see Illustration 9$)^{37}$. The aim is to help the audience discover and make more of jokes that are likely to have gone unnoticed, while at the same time heightening the viewers' awareness of such references. Under the heading "The Stuff You May Have Missed" the viewer (now turned reader) even gets explanations which refer to especially fast, complicated or hidden and esoteric hints and (meta)references. All these explanations do not merely serve the purpose of quenching the audience's curiosity, they are rather meant to spur and enhance $i^{38}$. Being 'instructed' by the guidebooks, the viewers are at the same time set on the trail to autonomously seek, discover and understand yet more references ${ }^{39}$. They are thus not only attuned to

37 Cf. Grey: "Simpsons snobbery also frequently took the form of proud declarations of being able to see the show's 'deeper' levels that many others were supposedly unable to see" (2006: 138). In a certain way the category "The Stuff You May Have Missed" is more or less directly addressed to this part of the audience. Up to now the series of guide books spans four volumes, published between 1997 and 2005, and covers seasons 1 to 14 . In spring 2010 the series is in its $21^{\text {st }}$ season.

38 Cf. Norrick: "[...] intertextual humor [...] depends on recognition of some source text. The teller presumably displays knowledge of the intended reference and challenges the audience to discover it. Their laughter at the right moment shows they have recovered the source text and got the joke" (1989: 118). Cf. also Norrick: "Failure to get this joke, and hence to pass the test its teller poses, shows a lack of presumably general cultural knowledge and signals nonmembership in cultural groups more obviously than an intelligence deficiency" (ibid.: 121). Since The Simpsons is a TV show that (thanks to its numerous re-runs and its availability on tape and DVD) can also be watched and rewatched alone, the viewer can realize his or her failures and subsequently acquire the necessary knowledge in order to 'pass the test' in a new attempt.

39 Cf. Irwin/Lombardo: "The writers recognize that not everyone will catch all the allusions, and so they craft them in such a way that the allusions enhance our enjoyment if they are caught, but do not detract from the enjoyment of the show if they are missed" (2001: 88). Gray warns of the danger of merely 'constructing' non-existing television audiences for the purposes of academic study out as 'fans' or 'engaged 


\section{HOW TO READTHE GUIDE}

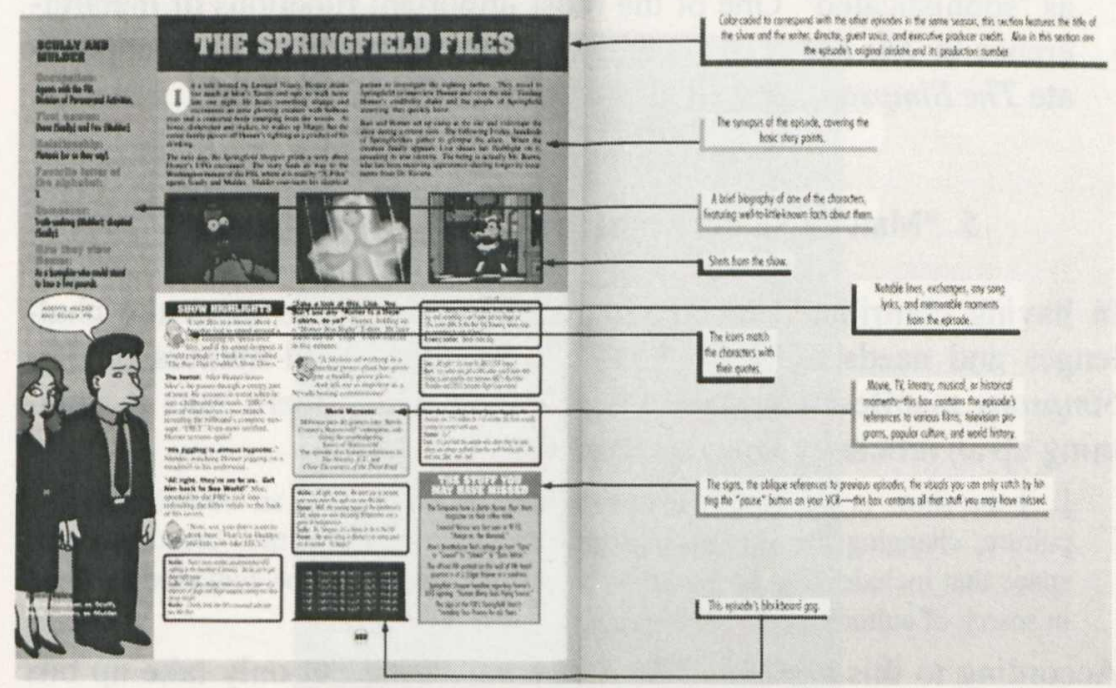

Illustration 9: Excerpt from The Simpsons: A complete Guide to Our Favourite Family (2006).

the style and functioning of the show, but also urged to form a kind of community with the producers ${ }^{40}$ as well as with others viewers a community (whose construction was certainly facilitated and made easier by the growth of the Internet during the mid-nineties) ${ }^{41}$ which defines itself via a shared and common horizon of cultural and historical knowledge ${ }^{42}$ and which will eventually begin to in-

viewers' (cf. 2006: 72 ) - however, in the case of The Simpsons it is actually possible to discern several types of audiences by looking at blogs, fan-made websites and the discussions in online panels. Cf. also Ortved 2009: 179.

40 Ortved quotes Erik Wirtanen, the founder and administrator of one of the most popular Simpsons web discussion groups: "The level of discourse [...] created a body of evidence for the creators to note, 'Hey, what we're doing is working. Let's do more of it. They like this hidden stuff.' It allowed the show to continue because it proved that it worked". (2009: 181)

${ }^{41}$ Cf. Alberti summing up an essay by Sloane: "[...] Sloane speculates about the relationship between fans of the show and the creative staff, particulary as manifested in the increasing interactivity between producer and consumer afforded by cyberculture". (2004: xxv)

42 Cf. for this Cohen 1999: 29 and Irwin/Lombardo: "One of the most important aesthetic effects allusion can have is the 'cultivation of intimacy' and the forging of 
creasingly expect such references from shows likewise conceived as 'sophisticated'. One of the most important functions of metareference in The Simpsons is thus to create an audience fit to appreciate The Simpsons as well as the genre and medium used ${ }^{43}$.

5. "Matt Groening? What's he doing in a museum?"

In having contributed to creating an audience fit to meet the challenges and needs of their show, the producers and authors of The Simpsons manifest a certain power ${ }^{44}$ - as John Alberti puts it, summing up an article by Douglas Rushkoff:

[...] the show is not simply a commentary on culture but an intervention into culture, changing the very mediaspace it comments upon, thus creating a new space that includes The Simpsons as part of the territory to be contested by those in search of cultural power. (2004: xxix)

According to this position, The Simpsons would not only take up bits and pieces of our cultural heritage in order to (sometimes cuttingly) comment upon them, but it would thus also take possession of the fields into which it ventures by so doing, at the same time altering these territories through partly modelling them according to the show's demands. Concerning the territory of the arts, the journalist Tad Friend already foresaw such a process:

$[\ldots]$ good art that reaches thirty million people and makes them feel connected may have more to offer us now than great art that reaches three thousand and makes them feel more or less alone. In our time the standards for art have changed, expanded. The future belongs to Bart Simpson. (1993: 124)

Matthew Henry, in 1994, was still sceptic about that, maintaining that

Friend's bold statement $[\ldots]$ poses some difficult questions for the academic: how, exactly, does the future belong to Bart Simpson? why should it belong to

community. The clear advantage of making allusions that draw on information that not everyone possesses is that they strengthen the connection between the author and the audience". (2001: 86)

43 Cf. Ortved quoting Seth McFarlane on The Simpsons: "It's like what sci-fi-fans say about Star Trek: it created an audience for that genre". (2009: 283)

44 Cf. also Rushkoff: "Television programmers are not programming television sets or evening schedules; they are programming the viewers" (2004: 293). Concerning their power in the context of the Fox Broadcasting Company which produces and airs The Simpsons cf. Gray 2006: 161-164, who states that "The Simpsons' writers and itself as a show has gained power with time" (172), as well as Alberti 2004: xxii and Ortved 2009: 234-240. 
him? and if so, what are the social and political implications of such dominance? (86)

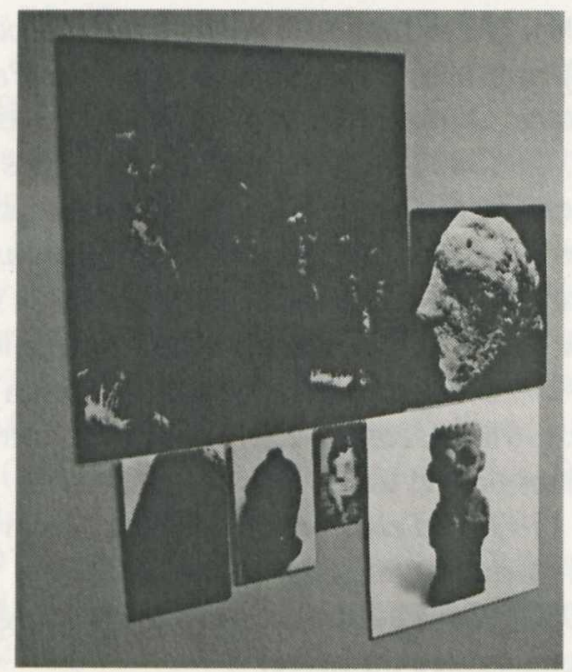

Illustration 10: Luis Jacob, detail from Album III (2004).

Henry's questions were answered - if only in part, but most directly ten years later in an artwork, created in 2004 by Canadian artist Luis Jacob and exhibited in 2007 at the documenta 12 in Kassel, where Jacob presented an installation consisting of two series of photographs including the work Album III. Among other, it showed photographs of stone sculptures such as, e. g., the so-called moai, the famous monumental statues on the Easter Island. However, planted among these images of dignified historical artefacts one could also encounter well known features such as large, oval eyes, a big mouth with an overbite, four fingers and a very distinctive, spiky hairdo in a small statue which represented no one else than Bart Simpson (see Illustration 10). Thus, tables seem to have turned: while before The Simpsons quoted art, now art is quoting The Simpsons. Indeed, "the future belongs to Bart Simpson" - as well as, one may add, to the intense metareference to which The Simpsons, like so many of contemporary media products, testify. 


\section{References}

Alberti, John (2004). "Introduction". Alberti, ed. xi-xxxii.

-, ed. Leaving Springfield: The Simpsons and the Possibility of Oppositional Culture. Detroit, MI: Wayne State University Press.

Arnold, David L. G. (2001). "And the Rest Writes Itself": Roland Barthes Watches The Simpsons". Irwin/Conard/Aeon, eds. 252-268.

- (2004). "Use a Pen, Sideshow Bob': The Simpsons and the Threat of High Culture". Alberti, ed. 1-28.

Astruc, Alexandre (1948). "Naissance d'une nouvelle avant-garde -

La Caméra-stylo". L'écran français 144 (30 March) : 5-13

Berri, Claude, dir. (1986). Jean de Florette. Film. France/Switzerland/ Italy: DD Productions, et al.

Bianculli, David (1992). Teleliteracy: Taking Television Seriously.

New York, NY: Continuum.

Borel, France (2002). Le Peintre et son miroir: Regards indiscrets. Tournai: La Renaissance du Livre.

Butler, Martin, Arvi Sepp (2007). "Der Meta-Cartoon: The Itchy and Scratchy Show im amerikanischen Fernsehcartoon The Simpsons". Hauthal, Janine, Julijana Nadj, Ansgar Nünning, Henning Peters, eds. Metaisierung in Literatur und anderen Medien: Theoretische Grundlagen, historische Perspektiven, Metagattungen, Funktionen. Spectrum Literaturwissenschaft 12. Berlin/New York, NY: de Gruyter. 361-376.

Cantor, Paul (1997). "In Praise of Television: The Greatest TV Show Ever ('The Simpsons')". American Enterprise 8/5: 34-37.

Cohen, Ted (1999). Jokes: Philosophical Thoughts on Joking Matters. Chicago, IL: University of Chicago Press.

Daniels, Dieter (2002). Kunst als Sendung: Von der Telegrafie zum Internet. Munich: Beck.

Ford, Simon (2004). The Situationist International: A User's Guide. London: Black Dog.

Friend, Tad (1993). "Sitcoms, Seriously". Esquire (March 1993): 112-125.

Gould, Stephen Jay (1977). Ontogeny and Phylogeny. Cambridge, MA: Harvard University Press.

Gray, Jonathan (2006). Watching with 'The Simpsons'. New York, NY: Routledge.

Groening, Matt, Ray Richmond, Antonia Coffman, eds. (1997). The Simpsons: A Complete Guide to Our Favorite Family. London: Harper Collins. 
Henry, Matthew (1994). "The Triumph of Popular Culture: Situation Comedy, Postmodernism and The Simpsons". Studies in Popular Culture 17/1: 85-99.

Hurd, Earl, dir. (1918). Bobby Bumps Puts a Beanery on the Bum. Film. USA: Bray Productions.

Hutcheon, Linda (1989). The Politics of Postmodernism. New York, NY: Routledge.

Irwin, William, J. R. Lombardo (2001). "The Simpsons and Allusion: 'Worst Essay Ever'”. Irwin/Conard/Aeon, eds. 81-92.

-, Mark T. Conard, J. Skoble Aeon, eds. The Simpsons and Philosophy: The D'Oh! Of Homer. Chicago, IL/La Salle: Open Court.

Jones, Charles M., dir. (1953). Duck Amuck. Film. USA: Warner Bros. Keazor, Henry (2003). "Kunst und Film bei den Simpsons". Kunsthistorische Arbeitsblätter 7/8: 37-46.

Korte, Dan (1997: online). "The Simpsons as Quality Televison". The

Simpsons Archive. http://www.snpp.com/other/papers/dk.paper. html [29/03/2010].

Matheson, Carl (2001). "The Simpsons, Hyper-Irony, and the Meaning of Life". Irwin/Conard/Aeon, eds. 108-125.

Mathieu, Marc-Antoine (1991). L'Origine. Paris: Delcourt.

- (1993). Le Processus. Paris: Delcourt.

McConnell, Frank (1990). "'Real' Cartoon Characters: 'The Simpsons"'. Commonweal 15 June: 389-390.

Michalski, Ernst (1932). Die Bedeutung der ästhetischen Grenze für die Methode der Kunstgeschichte. Berlin: Deutscher Kunstverlag.

Mittell, Jason (2001). "Cartoon Realism: Genre Mix and the Cultural Life of The Simpsons". The Velvet Light Trap 47: 16-28.

Mullen, Megan (2004). "The Simpsons and Hanna-Barbera's Animation Legacy". Alberti, ed. 63-84

Norrick, Neal R. (1989). "Intertextuality in Humor". Humor: International Journal of Humor Research 2/2: 117-139.

Ortved, John (2009). The Simpsons: An Uncensored, Unauthorized History. New York, NY: Faber and Faber.

Ozersky, Josh (1991). "TV's Anti-Families: Married ... with Malaise". Tikkun 6/1: 11-14, 92-93.

Petersen, Christer (2001). Jenseits der Ordnung: Das Spielfilmwerk Peter Greenaways. Strukturen und Kontexte. Kiel: Ludwig.

Plant, Sadie (1992). The Most Radical Gesture: The Situationist International in a Postmodern Age. London/New York, NY: Routledge.

Rushkoff, Douglas (2004). "Bart Simpson: Prince of the Irreverence". Alberti, ed. 292-301. 
Savage, Jr., William J. (2004). “'So Television's Responsible': Oppositionality and the Interpretive Logic of Satire and Censorship in The Simpsons and South Park". Alberti, ed. 197-224.

Schreiber, Dominic (1998: online). "Cult Heroes and Their Secrets". Animation Wold Magazine, 3/1. http://www.awn.com/mag/ issue3.1/3.1 pages/3.1 shreibercult.html [29/03/2010].

Schuster, Michael (1998). Malerei im Film: Peter Greenaway. Hildesheim/Zurich/New York, NY: Georg Olms.

Stabile, Carol A., Mark Harrison (2003). "Introduction: Prime Time Animation - an Overview". Carol A. Stabile, Mark Harrison, eds. Prime Time Animation: Television Animation and American Culture. London/New York, NY: Routledge. 1-11.

Stevenson, Robert, dir. (1964). Mary Poppins. Film. USA: Walt Disney Productions.

Stirling-Maxwell, William (1855). Velázquez and his Works. London: W. Parker and Son.

Stoichita, Victor (1997). L'Instauration du tableau: Métapeinture à l'aube des temps modernes. Paris: Droz.

Streisand, Barbra, dir. (1983). Yentl. Film. UK/USA: United Artists, Barwood Films, Ladbroke Investments.

Turner, Victor (1969). The Ritual Process: Structure and Anti-Structure. London: Routledge \& Kegan Paul.

Wolf, Reva (2006). "Homer Simpson as Outsider Artist, or How Learned to Accept Ambivalence (Maybe)". Art Journal 65/3: 101111.

Zemeckis, Robert, dir. (1988). Who Framed Roger Rabbit? Film. USA: Amblin Entertainment, Silver Screen Partners III, Touchstone Pictures. 